TURIZAM

Volume 20, Issue 1

1-11 (2016)

ORIGINAL

SCIENTIFIC PAPER

\title{
Culinary Travel as New Approach for Cultural Tourism
}

\author{
Tomás López-Guzmán*, José Manuel Hernández-Mogollón**, Elide di Clemente*** \\ Received: March 2014 | Accepted: December 2015
}

\begin{abstract}
Gastronomy is emerging as one of the key elements for the development and promotion of tourist destinations, also having a positive influence both on increasing overnight stays as in the enhancement of primary sector of a certain geographic area. The methodology used to carry out this research study was based on the realization of a fieldwork with the objective of getting to know the tourist profile visiting the city of Cáceres, Spain and its feedback and motivations regarding gastronomy. The results of this research show the important relationship between culture and gastronomy and point out how cultural destinations can enhance visitor satisfaction through the promotion of its cuisine. The findings of this research point to the importance of gastronomy in the satisfaction of tourists visiting the city of Cáceres. Thus an enhancement of the same would, consequently, determine higher tourist satisfaction. This paper can contribute to the analysis of gastronomic tourism in Europe, contributing as a key element, in addition to the high level of response from tourists, the fact that surveys have been conducted at the restaurants themselves when the traveler was having lunch or dinner.
\end{abstract}

Key words: Gastronomic traveller, cultural tourism, tourism attraction, Cáceres, Spain.

\section{Introduction}

Tourism is going through a period of considerable changes in offer and demand nowadays. The evolution of tourism companies, low-cost airlines, and the travellers' tendency to take shorter but more frequent holidays throughout the year in different holiday destinations, is implying large changes in tourism strategies. Holidaymakers nowadays feel more and more attracted to experience new sensations rather than just enjoying sightseeing, which has been the traditional tourist activity for many years. In fact, sometimes travellers simply prefer to feel part of the lifestyle and the actual way of living in a place, rather than just observing a landscape, a building or a work of art in museum.

* Faculty of Labour Sciences. University of Córdoba (Spain). Agrifood Campus of International Excellence, ceiA3. C/ Adarve, 30 14071-Córdoba (Spain). tomas.lopez@uco.es

** Faculty of Business and Tourism. University of Extremadura. Avenida de la Universidad, s/n. 10003-Cáceres. jmherdez@unex.es

***Faculty of Business and Tourism. University of Extremadura. Avenida de la Universidad, s/n. 10003-Cáceres. ediclemente@unex.es 
Therefore, tourists are more and more often opting for travels where other senses are involved, so that they can enjoy the visit more and in a different way. In this regard, tourism based on gastronomy, wine or oil takes the lead. This way, travellers looking for new sensations regarding gastronomy (wine and oil) will experience a totally different sensorial perception, which according to Cohen and Avieli (2004) will make the tourist feel part of the environment, so this is far different than merely observing a place.

To this extent, "cuisine" is becoming a key element in promoting tourist destinations and numerous research studies on the subject confirm the relevance of the food (and the wine) to contribute to a good tourist experience (Harrington, Ottenbacher, 2010) and even to be considered as another resource for the tourist destination to be promoted (Smith, Costello, 2009). Likewise, gastronomy (and wine) is part of the environment and the social and cultural identity of a population, since it reflects a lifestyle depending on the geographic area because is a deep-rooted concept in the own culture and tradition (Mitchell, Hall, 2006). It is noteworthy to point out that this also involves a constant necessity of innovating with products and providing the places with appropriate services for tourists to have an added value and to compete with other destinations. In this regard, to get to know the gastronomy of a place can be the main tourist attraction to visit a region, and it is not necessarily taken as a second (or complementary) reason to visit a place (Stewart et al., 2008). This is due to the fact that food is a reflection of the own inhabitants' idiosyncrasy (Brunori, Rossi, 2001). Besides, in rural and urban areas, gastronomy and all elements related to it, play an important role as a leisure place (culinary exhibitions, gastronomy schools, among others), and as a place (production farms, wine cellars, oil presses, etc.) to carry out different types of activities which involve being in touch with nature (Alonso, Northcote, 2010; Ottenbacher, Harrington, 2013).

The aim of this paper is to present an analysis of how gastronomy can become a key factor to compete with cultural and tourist destinations. Thus gastronomy is taken as a basic tool to promote any geographic area. Particularly, in this paper the authors we will analyse the tourist's profile and aims when visiting the city of Cáceres, officially declared as World Heritage Site by UNESCO, and concretely, those tourists having lunch and dinner at the leading restaurants of the city, where the typical gastronomy of the area is offered.

\section{Background}

The scientific literature in the field of gastronomic tourism is based on different research studies. Among these publications, worth mentioning are the works of Hjalager and Richards (2002), Boniface (2003), Long (2003), Cohen and Avieli (2004) and two books directed by Professor Hall analysing gastronomy (Hall, et al., 2003) and wine (Hall ,et al., 200o). A wide variety of terms are used to establish a relationship between food and tourism (cuisine tourism, food tourism, gastronomy tourism, gourmet tourism, gastronomic tourism or culinary tourism) whose distinction is sometimes very diffuse (Hall, Sharples, 2003; Kivela, Crotts, 2005; Ignatov, Smith, 2006; Henderson, 2009). According to Ignatov and Smith (2006) it can define gastronomic tourism as a type of tourism in which regional products are consumed (including drinks), participating in the food production (from agriculture to cuisine schools).

Scientific literature covers gastronomic tourism in different parts of the world, underlying places in Asia due to the differences with occidental food, which is creating culinary trend. Nonetheless, in the last few years, South-American food is becoming more and more successful, especially Perú. Literature provides with documentary evidence about the relevance 
of gastronomic tourism in places such as Hong Kong (Mckercher et al., 2008; Horng, Tsai, 2012), and other Asiatic countries (Cohen, Avieli, 2004; Ab Karim, Chi, 2010), Israel (Hilleel, et al., 2013) and Turkey (Okumus, et al., 2007). In America, it finds experiences in Argentina (Schülter, 2003), Canada (Stewart, et al., 2008), Chile (Ascanio, 2009) and Uruguay (Alonso, 2013). In Europe it finds other documents such as in Croatia (Fox, 2007), Finland (Tikkanen, 2007), France (Harrington, Ottenbacher, 2010), Germany (Ottenbacher, Harrington, 2013), Hungary (Metro-Roland, 2013), Italy (Ab Karim, Chi, 2010), Portugal (Texeira, Ribeiro, 2013) and Spain (López-Guzmán, Sánchez Cañizares, 2012; Alonso, Liu, 2012).

According to Henderson (2009) it has highlight three lines of research focused on the relationship between food and tourism. The first one to mention is the role of food as a tourism product, where the food festival and farmers markets are covered. The second one is the food marketing for tourists, including all aspects related to events and culinary festivals (Smith, Costello, 2009) as well as restaurants with a relevant importance worldwide. And last but not least, it will focus on the analysis of gastronomic tourism as an instrument to promote a destination for its general development. This will imply the food to be attractive for the tourist, in order to compete as a favourite destination, as well as business strategies for agricultural producers and food industries to enhance the relationship between gastronomy, culture and tourism. On the other hand, scientific literature (Tikkanem, 2007) underlines the fact that gastronomy (and wine) creates a synergy with tourism through different variables. As mentioned before, the first one implies gastronomy to be encouraged as an attraction so that the place in particular can be considered a gastronomic destination, and thus used as a resource to boost and advertise a geographic area (Smith, Costello, 2009). The second one could be to promote gastronomic routes (Hillel, et al., 2013); and the third one, could be to promote one or several places where gastronomy has an important role, so that it becomes an attraction. In the fourth place, different gastronomic events could be held as a cultural phenomenon (Smith, Costello, 2009). Depending on how close this connection amongst food and culture is, and the natural resources a place offers, gastronomic tourism will have a higher or a lower development as a consequence (Riley, 2005; Smith, Costello, 2009). There is no doubt anyhow that food plays an important role for the tourist and that it is part of the social and cultural heritage of a destination (Ignatov, Smith, 2006). Therefore, this type of tourism reinforces the importance of several aspects such as: using local ingredients, a constant process of learning and improving, consuming own products and having culinary resources produced in the geographic area in particular. On the other hand, to promote a cultural destination for its gastronomy, it should count on many basic characteristics, such as gastronomic resources that are recognizable for the travellers, and numerous and varied restaurants where this type of regional food can be ordered.

Gastronomy should then be taken into account as a very important tool to promote a determined cultural and tourist destination. Such places should consider food and wine as a contribution to that unique experience the traveller wants to live, as part of the culture of the geographical area the tourists visiting. Cuisine can definitely be considered as a tool to satisfy the traveller and provide with authenticity to the destination, so it enhances a social-economic impact on local gastronomic tourism (Du Rand, et al., 2003). A tourist destination is far more than a variety of natural, cultural and artistic resources. It should also impress the tourist who is looking for new experiences (Cracolici, Nijkamp, 2008). Having said all that, we might consider that holidaymakers look for a balance between the new (the different) and the innovative (Tse, Crotts, 2005). Thereby, it is still necessary to keep touristic resources to develop culinary tourism as well. For that purpose, according to Ignatov and Smith (2006) and Horng and Tsai 
(2013), it is indispensable to count on facilities (buildings, routes, etc.) in order to plan activities, events and further arrangements. To sum up, destinations ought to include gastronomy (food and wine as a cultural resource) to contribute to the traveller's unique experience (Haveng-Tang, Jons, 2005).

\section{Geographical area description}

The selected scenario to carry out this present research study is the city of Cáceres, in the South Western region of Extremadura in Spain, pretty close to the border with Portugal. Due to its characteristics, this city can be considered as a representative destination for cultural tourism in a national context. It is one of the most populated urban areas of the region with 95,668 inhabitants (National Statistics Institute of Spain -NSI-, 2012).

The economy of the city is primarily based on the service sectors, which is principally tourism. The city was declared to be World Heritage Site by UNESCO in 1986, so that implies that the city offers a great deal of cultural resources. Its old town is recognized as one of the best historical sites in Spain, having been enlisted as one of the best-conserved places (Ortega, et al., 2012).

Regarding its success as a tourist destination, it may observe the statistics related to the number of travellers and overnight stays that the city recorded in the years 2007-2012, whose data are shown in Tables 1 and 2.

Table 1. Number of travellers hosted by Cáceres between 2007-2012

\begin{tabular}{|c|c|c|c|}
\hline Year & Total & Spanish & Other nationalities \\
\hline 2007 & 213,383 & 187,980 & 25,403 \\
\hline 2008 & 201,187 & 176,357 & 24,830 \\
\hline 2009 & 206,973 & 183,021 & 23,952 \\
\hline 2010 & 215,490 & 192,783 & 22,706 \\
\hline 2011 & 233,053 & 202,811 & 30,242 \\
\hline 2012 & 223,071 & 192,464 & 30,607 \\
\hline
\end{tabular}

Source: NSI (2013)

Table 2. Number of overnight stays in the city of Cáceres in 2007-2012

\begin{tabular}{|c|c|c|c|}
\hline Year & Total & Spanish & Other nationalities \\
\hline 2007 & 342,243 & 300,590 & 41,653 \\
\hline 2008 & 336,971 & 295,418 & 41,553 \\
\hline 2009 & 326,969 & 286,717 & 40,252 \\
\hline 2010 & 341,579 & 306,930 & 34,644 \\
\hline 2011 & 368,701 & 326,394 & 42,306 \\
\hline 2012 & 358,549 & 312,216 & 46,333 \\
\hline
\end{tabular}

Source: NSI (2013)

As it may observe in both tables, the main tourists visiting the city are Spanish, reaching a $90 \%$ in the number of travellers and overnight stays. The number of overnight stays is still low though, but tourists from other nationalities increase that figure. In that aspect, we con- 
sider that a reinforcement of the gastronomic culture in the city could also increase the number of tourists coming from different nations to visit the city, increasing thus, the number of overnight stays.

Apart from being considered historic and artistic cultural heritage of great value, the city of Cáceres can also promote its wonderful local gastronomy, identified by the use of first-quality raw materials aside from a strong cultural identity. The latter is the result of a long process to create local culinary tradition that represents an important tool to understand and learn social, political and cultural events that have left a memory in the eating habits as well as in the preparation of local products and typical dishes. Many of the labelled food as typical gastronomy in this city are certified to be Designation of Origin, and according to Harrington and Ottenbacher (2010), such classifications reinforce the origin and quality of agriculture production as well as the cultural identity of the city using "terroir" to create a unique and memorable experience. Amongst those products certified as Designation of Origin, we have: Jamón Dehesa de Extremadura (Spanish cured ham), Cereza del Jerte (cherry), Aceite Gata-Hurdes (olive oil), Miel de Villuercas-Ibores (special honey), Torta del Casar (biscuit-cake with cheese), Queso Ibores (cheese) and Pimentón de la Vera (special Paprika delicatessen). In this regard, they are products that have been produced in the nearby rural areas of Cáceres, so this is what makes them so special, apart from having organoleptic properties due to the good weather conditions, the traditional production processes and the geographical situation of this zone. In this aspect, fresh wild meat represents one of the distinctive elements of the gastronomic traditions of the city, being base of many of the typical recipes and dishes (such as quail, partridge, deer and wild pig among others) (Ortega, et al., 2012). Anyway, the most highlighted product of the local traditional food is still the Iberian swine and all its derivative products (ham, sausage, and further meat products).

A great deal of restaurants in the city highlights their exquisite meals, their geographical situation and their chef's talent. Some of them are even recommended by the main national and international guides, such as the Michelin Guide. Most of the typical restaurants are in the monumental and historical area of the city, which offers the traveller a unique opportunity to enjoy a delicious meal in a singular and cultural atmosphere.

\section{Methodology}

The methodology used to carry out this research study was based on the realization of a field of research with the objective of getting to know the tourist profile visiting the city of Cáceres and its feedback and motivations regarding gastronomy.

The aim was to find out the tourists' opinions about the development and consolidation of this touristic destination, essentially cultural from a gastronomic point of view. In order to carry out this field of research several surveys were conducted at the restaurants when tourists were having lunch or dinner. The restaurants selected to conduct the survey were those considered to be the most representative ones for regional food. The authors considered that selecting the restaurant as well as the place where the survey was conducted reinforces the quality of the research, and thus the results obtained.

The structure of the survey for this research is based on different previous works (Ignatov, Smith, 2006; Okumus, et al., 2007; López-Guzmán, Sánchez-Cañizares, 2012) and responds to five aspects: social-demographic characteristics of the tourist, economic profile, motivations or reasons, feedbacks and opinions. 
The surveys were conducted amongst the months of April and May 2012. The participants filled the forms on their own, although surveyors who were present at that very moment had some difficulty understanding. The survey was absolutely anonymous. There was a previous test with 20 surveys to detect possible mistakes. The total number of surveys was 720 .

The items used were aimed to respond to indicators and measures proposed to analyse the demand and in order to compare systems between different gastronomic destinations (Fox, 2007). Several technical questions were submitted to study through a Likert scale of 5 points to give a grading mark for motivation and expectations, giving yes/no answers and closed/open questions, where they could leave their comments with regards to the gastronomic experience. The total number of tourists visiting the city in 2011 was 233,053 (NSI, 2012). The sample error of the research was $+/-3.7 \%$. The technical file is shown in table 3 .

Table 3. Technical file of the research on the demand

\begin{tabular}{|l|l|}
\hline Number of tourists (year 2011) & 233,053 travellers \\
\hline Sample & 720 surveys \\
\hline Sample error & $+/-3.7 \%$ \\
\hline Trusting level & $95 \%$ \\
\hline Procedure & Simple random sampling \\
\hline Period of time & April-May 2012 \\
\hline Control of sample & Realization and supervision of the work of field by the researchers \\
\hline
\end{tabular}

Source: own elaboration

These data were analysed and arranged in charts using the SPSS 15.0 programme. The data processing has been realized by means of statistical tools that were univariant and bivariant.

\section{Results and discussion}

Social-demographic characteristics of the tourist visiting the city of Cáceres are shown in Table 4.

Table 4. Social-demographic characteristics of the tourist visiting the city of Cáceres

\begin{tabular}{|l|l|c|l|l|c|}
\hline \multicolumn{2}{|c|}{ Variable } & Percentage & \multicolumn{2}{c|}{ Variable } & Percentage \\
\hline $\begin{array}{l}\text { Gender } \\
(\mathrm{N}=693)\end{array}$ & Men & $\begin{array}{c}49.4 \% \\
50.6 \%\end{array}$ & $\begin{array}{l}\text { Education } \\
(\mathrm{N}=701)\end{array}$ & $\begin{array}{l}\text { High School or lower } \\
\text { Technical education } \\
\text { University }\end{array}$ & $\begin{array}{c}29.8 \% \\
12.7 \% \\
57.5 \%\end{array}$ \\
\hline Age & Younger than 30 & $15.6 \%$ & Monthly & Lower than 1,000 euros & $18.2 \%$ \\
$(\mathrm{~N}=710)$ & $30-39$ years old & $22.5 \%$ & wage & From 1,000 to 1,500 euros & $26.6 \%$ \\
& 40-49 years old & $23.8 \%$ & $(\mathrm{~N}=595)$ & From 1,501 to 2,000 euros & $24.4 \%$ \\
& 50-59 years old & $23.5 \%$ & & More than 2,000 euros & $30.9 \%$ \\
& 60 or older & $14.6 \%$ & & & \\
\hline
\end{tabular}

Source: own elaboration

With regards to the social-demographic profile of the tourist taking part in the survey, it is worth mentioning that most of them were Spanish visitors (90.8\%), thus Cáceres has become a touristic destination of national interest. Regarding their educational level, a vast majority of them had University studies. The results confirm the prior research studies (Kivela, Crotts, 
2006; Ignatov, Smith, 2006; McKercher, et al., 2008; López-Guzmán, Sánchez Cañizares, 2012) and it reinforces the fact that gastronomic tourism involves an elevated academic level, as well as cultural tourism. With reference to the age, there is a great similarity among three ranges, confirmed by (Kivela, Crotts, 2006), where conclusions are also similar. Likewise, it can affirm that tourists arriving in this city have a high economic level, actually a $29.6 \%$ admits that their incomes are higher than 2,00o euros a month. In regard to the length of their stay, the majority (37.1\%) stay only for one night, whereas a $27.9 \%$ spends 3 to 7 days in the city and a $27.3 \%$ does not stay for the night. For a $48.1 \%$ it was the first visit to the city. Most of the surveyed visitors were travelling with their partner $(44.2 \%)$, with colleagues or friends (34.0\%). It has been detected that there is a connection between the level of revenues and gender (Pearson's chisquared coefficient $=17.889 ; \mathrm{p}=0.000$ ), the age (Pearson's chi-squared coefficient $=131.682 ; \mathrm{p}=$ o.ooo) and their educational level (Pearson's chi-squared coefficient $=78.185 ; \mathrm{p}=0.000$ ).

Regarding the motivations to visit the city, the main reasons are shown in Table 5 . These have been measured in a Likert scale of 5 points, being 1 - barely important; and 5 - very important.

Table 5. Reasons for visiting Cáceres

\begin{tabular}{|l|l|}
\hline Motivation & \\
\hline Culture & 4.07 \\
\hline Gastronomy & 3.90 \\
\hline Relax & 3.40 \\
\hline Leisure & 3.39 \\
\hline To visit friends or family & 2.39 \\
\hline Educational & 2.25 \\
\hline To practise sport & 1.84 \\
\hline Business or work & 1.75 \\
\hline Medical reasons & 1.34 \\
\hline
\end{tabular}

Source: own elaboration

According to the data in the Table 5, there are two main reasons why tourists visit the city, and these are to get to know the culture and the artistic monuments, as well as to enjoy its gastronomy. Following the scientific literature (Schlüter, 2003; Fox, 2007), the cultural tourist and the gastronomic tourist are very similar. In fact, focusing on enjoying gastronomy, the average feedback is high (4 points). Such result reinforces the importance of gastronomy in the city to be considered as a good touristic destination, as well as having historical and cultural heritage.

Regarding the feedback on certain elements of the local gastronomy, the main results obtained from the tourists visiting Cáceres are shown in table 6. Such results are exposed in a Likert scale of 5 points, being 1 - barely important; 5- very important.

According to the Table 6 it can see that the most valued elements for the tourists are traditional cooking and hospitality from restaurants of the city. Likewise, and in a negative aspect, the prices and the lack of innovation and new flavours has been underlined and criticized in further research studies in Spain (López-Guzmán, Sánchez-Cañizares, 2012). In this regard, it would be necessary for the restaurants to innovate more, basing on the own gastronomy, but creating new flavours and gastronomy trends.

Regarding typical dishes considered as the favourite ones for the tourists, are ham $(76.1 \%)$ and "torta del Casar" (biscuit with cheese) (50.4\%). However, solely a $45.2 \%$ of the tourists 
Table 6. Elements related to the gastronomy of the city of Cáceres

\begin{tabular}{|l|l|}
\hline Gastronomy aspects & \\
\hline Traditional gastronomy & 4.21 \\
\hline Service and hospitality & 4.13 \\
\hline Quality of the menus & 3.97 \\
\hline Atmosphere in the restaurants & 3.83 \\
\hline Facilities & 3.80 \\
\hline Innovation on the menus & 3.55 \\
\hline Prices & 3.51 \\
\hline
\end{tabular}

Source: own elaboration

knows about the wine of this geographic zone (Designation of Origin) and their feedback is a 3.79 point of quality (in a Likert scale of 5 points), being the lowest mark in the range of local gastronomy products considered Designation of Origin.

As far as we are concerned, this result ought to suggest that products that are labelled Designation of Origin and the connection between gastronomy and the wine of the area should be promoted as a basic element to consolidate gastronomy in a tourist destination.

Another fundamental aspect of the survey was to get to know the behaviour when purchasing gastronomy products of this geographic area in their hometowns. In this sense, a $27.8 \%$ of the tourists consider that they are used to consuming gastronomic products of this geographic area in their hometowns, and a $40.3 \%$ say that they consume it at some occasions. In this regard, we consider that it is very important to reinforce the existing relationship between tourism and gastronomy, and the image of the culinary products of a geographic area, that will be purchased in their hometowns afterwards.

With reference to the level of general satisfaction after visiting the city of Cáceres, the average mark has been 4.34 in a Likert scale of 5 points. A $46.3 \%$ of the tourists were very satisfied after the visit and a $43.5 \%$ were satisfied enough. No connections have been detected between the level of satisfaction, gender, age, educational level or monthly wages. Regarding the general satisfaction level and in a Likert scale of 5 points, the mark has been 4.10 . A $33.5 \%$ of the persons who participated in the survey were very satisfied and a $46.4 \%$ were satisfied enough. No connections were detected either amongst factors such as gender, age, educational level and monthly wage regarding the satisfaction with gastronomy.

\section{Conclusions}

Gastronomic tourism is defined nowadays as one of the greatest ways to promote or consolidate touristic destinations, due to the importance it has for the travellers to get to know about the gastronomic culture of the places they visit. There are actually certain travellers who consider very important to go to a restaurant in a place they visit in order to get to know the regional food and culinary aspects of the area. In this paper we have merely presented a reflection about the existing relationship between tourism and gastronomy. Firstly, a brief summery of the scientific literature in the field of gastronomic tourism has been provided, where the fact that cuisine is becoming a more and more important aspect to bear in mind, has been proved to be a key factor to compete as a tourism destination in certain areas. 
Likewise, the results have been provided from a field of research that has been conducted to tourists visiting the city of Cáceres while they were having lunch or dinner in local restaurants. The main results of this research study allow us to confirm the importance of gastronomy as part of the experience travellers are looking for, especially in cultural places, as well as the high economic level of the tourists and the important satisfaction level they have regarding the cultural heritage and the gastronomy of Cáceres, highlighting the traditional gastronomy and the service and the hospitality and it is necessary to strengthen the innovation on the menus

As a future line of research, the authors consider that the purchase behaviour of the tourists visiting a determined geographic area should be analysed, and finally how they purchase agricultural products of this zone afterwards.

Finally, and as a major limitation of this research study, the authors should take into account the temporary period, in which this research has taken place, as it would also be interesting to know other tourists' opinions visiting the city at other periods of time of the year.

\section{References}

Ab Karin, S., Chi, C. 2010. Culinary tourism as a destination attraction: an empirical examination of destinations' food image. Journal of Hospitality Marketing and Management, 19, 321-355.

Alonso, A.D. 2013. Tannat: the positioning of a wine grape as symbol and referent of a nation's gastronomic heritage. Journal of Heritage Tourism, 8 (2-3), 105-119.

Alonso, A.D., Liu, Y. 2012. Old wine region, new concept and sustainable development: winery entrepreneurs'perceived benefits from wine tourism on Spain'Canary Islands. Journal of Sustainable Tourism, 20 (7), 991-1009.

Alonso, A.D., Nortcote, J. 2010. The development of olive tourism in Western Australia: A case study of an emerging tourism industry. International Journal of Tourism Research, 12, 696708.

Ascanio, A. 2009. Rutas gastronómicas chilenas: una aproximación al tema. Journal of Tourism and Cultural Heritage, 7 (2), 321-325. (in Spanish)

Boniface, P. 2003. Tasting tourism: travelling for food and drink, Ashgate Publishing Limited, Aldershot, 185

Brunori, G., Rossi, A. 200o. Synergy and coherence through collective action: some insights from wine routes in Tuscany. Sociologia Rurales, 40 (4), 409-4.23.

Cohen, E., Avieli, N. 2004. Food in tourism: attraction and impediment. Annals of Tourism Research, 31 (4), 755-778.

Cracolici, M.F., Nijkamp, P. 2008. The attractiveness and competitiveness of tourist destinations: A study of Southern Italian regions. Tourism Management, 30, 336-344.

Du Rand, G.E., Heath, E., Alberts, N. 2003. The role of local and regional food in destination marketing: A South African situation analysis. Journal of Travel and Tourism Marketing, 14 (3/4), 97-112.

Fox, R. 2007. Reinventing the gastronomic identity of Croatian tourist destinations. International Journal of Hospitality Management, 26, 546-559.

Hall, C.M., Sharples, L., Cambourne, B., Macionis, N. 200o. Wine tourism around the world: development, management and market, Elsevier, Oxford, 322 pp.

Hall, C. M., Sharples, L., Mitchell, R., Macionis, N., Cambourne, B. 2003. Food tourism around the World, Butterworth-Heinemann, Oxford, 272 pp. 
Hall, C. M., Sharples, L. 2003. The consumption of experiences or the experience of consumption?. An introduction to the tourism of taste, in Hall, C. M., Sharples, L., Mitchell, R., Macionis, N., Cambourne, B. (Ed.), Food tourism around the World, Butterworth-Heinemann, Oxford, pp. 1-24.

Harrington, R.J., Ottenbacher, M.C. 2010. Culinary tourism. A case study of the gastronomic capital. Journal of Culinary Science and Technology, 8, 14-32.

Haveng-Tang, C., Jons, E. 2005. Using local food and drink to differentiate tourism destinations through a sense of place: A store from Wales-Dining ar Mommouthshire's Great Table. Journal of Culinary Science and Technology, 4 (4), 69-86.

Henderson, J.C. 2009. Food tourism reviewed. British Food Journal, 111 (4), 317-326.

Hjalager, A.M., Richards, G. 2002. Tourism and Gastronomy, Routledge, London, 238 pp.

Hillel, D., Belhassen, Y., Shani, A. 2013. What makes a gastronomic destination attractive? Evidence from the Israeli Negev. Tourism Management, 36, 200-209.

Horng, J.S., Tsai, C. 2010. Government websites for promoting East Asian culinary tourism: a cross-national analysis. Tourism Management, 31, 74-85.

Ignatov, E., Smith, S. 2006. Segmenting Canadian culinary tourist. Current Issues in Tourism, 9 (3), 235-255.

Kivela, J., Crotts, J. 2005. Gastronomy tourism: A meangful travel market segment. Journal of Culinary Science and Technology, 4 (2/3), 39-55.

Kivela, J., Crotts, J. 2006. Tourism and gastronomy: gastronomy's influence on how tourists experience a destination. Journal of Hospitality and Tourism Research, 30 (3), 354-377.

López-Guzmán, T., Sánchez-Cañizares, S. 2012. Culinary tourism in Cordoba (Spain). British Food Journal, 114 (2), 168-179.

Long, L. 2003. Culinary Tourism. University of Kentucky Press, Lexington, 309 pp.

McKercher, B., Okumus, F., Okumus, B. 2008. Food tourism as a viable market segment: It's all how you cook the numbers!. Journal of Travel and Tourism Marketing, 25 (2), 137-148.

Metro-Roland, M.M. 2013. oulash nationalism: the culinary identity of a nation. ournal of Heritage Tourism, 8 (2-3), 172-181.

Mitchell, R., Hall, C.M. 2006. Wine tourism research: the state of play. Tourism Review International, 9 (4), 307-332.

National Statistics Institute of Spain 2013. Hotel occupancy Survey. NSI Publications, Madrid, 127 pp.

Okumus, B., Okumus, F., McKercher, B. 2007. Incorporating local and international cuisines in the marketing of tourism destinations: the cases of Hong Kong and Turkey. Tourism Management, 28, 253-261.

Ortega, F.J., Sánchez, J.M., Hernández, J.M. 2012. La gastronomía "de alta gama, de lujo o de calidad" como eje potenciador del turismo cultural y de sensaciones en Extremadura, Caja Extremadura Foundation, Cáceres.

Ottenbacher, M.C., Harrington, R. 2013. A case study of a culinary tourism campaign in Germany: implications for strategy making and successful implementation. Journal of Hospitality and Tourism Research, 37 (1), 3-28.

Riley, M. 2005. Food on beverage management. A review of change. International Journal of Contemporary Hospitality Management, 17 (1), 88-93.

Schlüter, R.G. 2003. Turismo y patrimonio gastronómico. Una perspectiva, Centro de Investigaciones y Estudios Turísticos, Buenos Aires, 191 pp. (in Spanish).

Smith, S., Costello, C. 2009. Segmenting visitors to a culinary event: motivations, travel behaviour and expenditures. Journal of Hospitality Marketing and Management, 18, 44-67. 
Stewarte, J.X., Bramble, L., Zirald, D. 2008. Key challenges in wine and culinary tourism with practical recommendations. International Journal of Contemporary Hospitality Management, 20 (3), 302-312.

Texeira, V.A.V., Ribeiro, N.F. 2013. The lamprey and the partridge: a multi-sited ethnography of food tourism as an agent of preservation and disfigurement in Central Portugal. Journal of Heritage Tourism, 8 (2-3), 193-212.

Tse, P., Crotts, J.C. 2005. Antecedents of novelty seeking: International visitors propensity to experiment across Hong Kong's culinary traditions. Tourism Management, 26, 965-968.

Tikkanem, I. 2007. Maslow's hierarchy and food tourist in Finland: five cases. British Food Journal, 109 (9), 721-734. 